\title{
INVENÇÃO OU CRIAÇÃO MATEMÁTICA E OS FENÔMENOS DIDÁTICOS
}

INVENTION OR MATHEMATICAL CREATION AND DIDACTIC PHENOMENA

\author{
Marcus Bessa de Menezes ${ }^{1}$ \\ ORCID iD: $\underline{0000-0003-0850-1793}$
}

Alvino Moser $^{2}$

ORCID iD: $\underline{0000-0001-7828-5067}$

\begin{abstract}
RESUMO
Este ensaio teórico tem por objetivo tratar da invenção matemática discutida por Jacques Hadamard e relacioná-lo à prática docente, a partir dos fenômenos didáticos existentes. Justifica esta pesquisa, o fato de que se a matemática é uma invenção ou criação, e este pressuposto precisa estar evidenciado nos objetivos do ensino, pois, em geral, os docentes almejam que os estudantes aprendam conteúdos clássicos e prontos para serem apropriados por eles. Na parte 2 do texto, apresenta-se o conceito definido por Hadamard sobre a invenção matemática, descrevendo as suas quatro fases: a preparação, a incubação, a iluminação e a verificação; e analisar, na perspectiva do autor, o papel do inconsciente na iluminação matemática, apoiado, sobretudo, no testemunho de Poincaré. Na parte 3, trata-se dos fenômenos didáticos que ocorrem na sala de aula de matemática (transposição e contrato) e seus papéis para a aprendizagem autônoma do aluno. A metodologia da pesquisa é bibliográfica e documental. Temos como principal contribuição a influência exercida pelos fenômenos, evidenciando que não basta adequar o saber a ser ensinado, mas também de verificar o que é efetivamente aprendido. A conclusão destaca que a aprendizagem, como fenômeno que se dá em primeira pessoa, exige a autonomia do aluno e, consequentemente, é necessário estimular seu potencial de criatividade que, ao invés de se contentar de se apropriar dos conteúdos produzidos por especialistas, procure construir seu próprio saber matemático, incentivando-o a ser, por sua vez, um inventor ou criador de soluções próprias.
\end{abstract}

Palavras-chave: Invenção matemática. Sala de aula de Matemática. Transposição didática. Aprendizagem autônoma.

\section{ABSTRACT}

This theoretical essay aims to address the mathematical invention discussed by Jacques Hadamard and to relate it to teaching practice, based on existing didactic phenomena. This research justifies the fact that if mathematics is an invention or creation, and this assumption needs to be evidenced in the teaching objectives, since, in general, the teachers want the students to learn classical contents and ready to be appropriated by them. In part 2, of the text, Hadamard's concept of mathematical invention is presented, describing its four phases: preparation, incubation, lighting and verification; and to analyze, in the author's perspective, the role of the unconscious in mathematical illumination, supported, above all, by Poincaré's testimony. In part 3, it deals with the didactic phenomena that occur in the mathematics classroom (transposition and contract) and their roles for the student's autonomous learning. The research methodology is bibliographic and documentary. We have as main contribution the influence

\footnotetext{
${ }^{1}$ Doutor em Educação pela Universidade Federal de Pernambuco (UFPE). Professor da Universidade Federal de Campina Grande (UFCG), Sumé, Paraíba, Brasil. Endereço para correspondência: Rua Engenheiro Saturnino de Brito Filho, 1079, Itararé, Campina Grande, Paraíba, Brasil, CEP: 58411-000. E-mail: marcusbessa @ gmail.com.

${ }^{2}$ Doutor em Filosofia pela Université Catholique de Louvain. Professor do Centro Universitário Internacional (UNINTER), Curitiba, Paraná, Brasil. Endereço para correspondência: Rua do Rosário, 147, Centro, Curitiba, Paraná, Brasil, CEP: 80020-110. E-mail: moseral.am@gmail.com.
} 
exerted by the phenomena, showing that it is not enough to adapt the knowledge to be taught, but also to verify what is effectively learned. The conclusion highlights that learning, as a phenomenon that takes place in the first person, requires the student's autonomy and, consequently, it is necessary to stimulate their potential for creativity which, instead of being content to appropriate the contents produced by specialists, seeks to build their own mathematical knowledge, encouraging him to be, in turn, an inventor or creator of his own solutions.

Keywords/Palabras clave: Mathematical Invention. Mathematics classroom. Didactic Transposition. Autonomous learning.

\section{INTRODUÇÃO}

Em 1989, a editora Odile Jacob publicou a discussão entre Jean-Pierre Changeux, prestigioso biólogo francês e Alain Connes, prêmio Fields de Matemática. A discussão é sobre o cérebro e o pensamento em relação à natureza ou origem dos objetos matemáticos. Nesse debate, entram em disciplinas como a neurologia, a mecânica quântica e a topologia.

Certamente, depois de mais de 20 anos em que as pesquisas neurológicas e a natureza da matemática evoluíram, as posições seriam apoiadas em outros argumentos. Caso mantivessem as mesmas convicções em relação a essas questões, Changeux continuaria a afirmar com melhores e mais argumentos que a matemática é o resultado da produção algorítmica que ocorre nas relações inter neuronais cerebrais e, por seu lado, Changeux afirmaria que a matemática é fruto de descoberta, apoiando-se como prova no teorema da incompletude de Kurt Gödel.

Cada uma das perspectivas, seja afirmando a matemática como uma criação cerebral (Changeux), seja considerando-a como descoberta (Connes), tanto a criação como a descoberta requerem um trabalho ou exercício para produzir ou descobrir as soluções para questões de matemática. Criação e descoberta não são inatas.

Tendo como pressupostos a teoria construtivista e a teoria platônica da matemática, o problema deste ensaio teórico é analisar a perspectiva de Jacques Hadamard em relação à invenção ou criação da matemática e suas possíveis implicações em sala de aula. Essa análise nos remete a algumas questões: Será a aprendizagem da matemática uma criação, uma invenção ou uma exploração? O professor de matemática, em sua prática, pode formar um criador inventivo de sua aprendizagem matemática, ou formará um explorador em sua aprendizagem neste domínio? Ou, o que mais ocorre, fazer do aluno um simples repetidor?

Portanto, esse ensaio justifica-se, pois, a elucidação da invenção ou criação matemática certamente poderá servir de referência aos professores de matemática para planejarem suas aulas e metodologia ano ensino. 
A metodologia da pesquisa é bibliográfica e documental, pois que Hadamard declara expressamente que se baseou em testemunhos de matemáticos, dentre os quais destacamos Henri Poincaré. E as análises dos fenômenos didáticos que emergem na sala de aula são também de cunho bibliográfico.

Assim, dividimos nosso ensaio em 3 partes. Na parte 1, apresentamos o problema definido pelos objetivos, a justificativa, as hipóteses e a metodologia. Em seguida, na parte 2, apresenta-se a perspectiva de Jacques Hadamard e o testemunho de Henri Poincaré sobre a invenção matemática. Cabendo à parte 3, o estudo da sala de aula de matemática como lócus em que emergem fenômenos didáticos. Considerar-se-ão a transposição didática, segundo Yves Chevallard, o contrato didático e o discurso educacional, bem como, o momento da invenção matemática. Após essas partes, seguem as considerações e as sugestões desse ensaio.

\section{A INVENÇÃO MATEMÁTICA SEGUNDO JACQUES HADAMARD}

No livro "Psicologia da invenção na matemática", Jacques Hadamard (2009) apresenta a distinção entre invenção e descoberta. Segundo o autor, a invenção ocorre quando se cria algo que não existe ou alguma coisa nova; ao passo que descoberta é apenas o desvendamento do que já existe, por exemplo, Colombo descobriu a América, Cabral descobriu o Brasil.

Há uma questão a ser elucidada no início deste tópico, que segundo Karine Chemla (CNRS, Centre National des Recherches Scientifiques), é uma questão clássica na filosofia da matemática: "A Matemática é invenção ou descoberta?" É questão de construção ou de desvelamento da realidade? (LEGLU, Dominique, 26/01/1999).

Sem dúvida, a resolução de problemas matemáticos exige várias construções intermediárias possíveis que permitem esta resolução. Será a construção mais relevante do que a invenção? Qual a relação entre construção invenção e criação? Há relação, mas não é a relação de sinonímia, pois a invenção e a criação são construções novas e inéditas. Esta discussão fez derramar muita tinta, e não pode ser resolvida em alguns parágrafos.

No âmbito deste artigo, subentendemos que a invenção e a criação supõem construções sem fazer identificação entre elas. Consideramos, então, a invenção e a criação.

Há muitas descobertas, invenções e construções em outras ciências e na poesia: Pasteur descobriu as bactérias; Galvani, a eletricidade animal; Benjamin Franklin inventou o para-raios; Arquimedes descobriu o empuxo da água e Santos Dumont inventou o avião, a hélice, para citar alguns casos e não faltam exemplos em poesia. 
Para esclarecer o que entende por invenção, Hadamard (2009, p. 13) afirma que a "matemática é um caso da invenção geral: este é um processo que pode ocorrer em vários domínios na ciência, na arte ou até na técnica". E acrescenta, “os filósofos modernos vão mais além, pois perceberam que a inteligência seria uma invenção constante $e_{2}$ a vida é uma perpétua invenção". (Idem, p. 14).

Sobre a invenção, Ribot (1900, p. 46):

A invenção das Belas Artes e nas ciências é um caso particular, na vida prática, nas invenções industriais, comerciais, nas instituições religiosas, sociais e políticas o espírito humano despendeu e fixou a mesma imaginação que em tudo mais.

Para Bergson (1901, p. 226):

O esforço da invenção, que se manifesta em todos os setores da vida com a criação de novas espécies, encontrou na humanidade o meio de se perpetuar por indivíduos, que, com a inteligência, possuem faculdade de iniciativa, independência e liberdade.

Hadamard estuda a invenção ou a criação da matemática considerando o que dizem os próprios matemáticos baseados em sua introspecção. Poderíamos classificar seu método como interpretativista ou compreensivista, entendendo esse viés metodológico segundo os paradigmas propostos por G. Morgan (1980). A compreensão e a interpretação diferem das perspectivas empíricas ou positivistas, isto é, não se vai considerar a criação dos matemáticos a partir do produto criado, objetivo, mas procura-se a explicação introspectiva que os próprios matemáticos apresentam em seus depoimentos. A esse respeito, Hadamard explica que não se pode descrever de fora o processo da invenção realizada pelos matemáticos. Para estudar a invenção na matemática, o melhor caminho é o testemunho biográfico, a introspecção. Então, procede estudando testemunhos e realizando a própria introspecção, citando casos ocorridos com ele mesmo.

Considerando a narração de Henri Poincaré apresentada numa conferência proferida na Sociedade de Psicologia de Matemática, segundo a qual depois de 15 dias de trabalho sobre as funções fuchsianas, sem resultado, sem saber se elas existiam ou não, resolveu não mais se ocupar delas. Após uma noite de insônia, ele construiu a primeira série dessas funções. Cita o mesmo matemático que escreve: "Eu quis representar essas funções (fuchsianas) pelo quociente de duas séries. Tal ideia foi perfeitamente consciente e pensada; guiava-me pela analogia com as funções elípticas. Indagava-me quais deveriam ser as propriedades dessas séries se existissem. " (POINCARÉ, apud HADAMARD, 2009, p. 27).

Mas, como se deu a descoberta? Conta ele, que deixava Caen-Fr, onde morava, para uma expedição geológica organizada pela sua escola. Quando pisou o pé no estribo do trem, 
veio-lhe subitamente uma iluminação de que as transformações que ele havia utilizado para definir as funções fuchsianas eram idênticas às geometrias não euclidianas. No momento não verificou, porque não havia tempo. Sendo esta verificação feita mais tarde na sua casa.

Portanto, ao chegar até o trem, teve a iluminação que difere da adivinhação. Esta última ocorre ao acaso, ao passo que a iluminação acontece depois de árduo trabalho, seguido por descanso ou distração. $\mathrm{O}$ espírito dispensa intermediários.

$\mathrm{Na}$ mesma conferência, Poincaré narra outros acontecimentos como o citado por Hadamard: Pôs-se, então, a estudar as questões de aritmética, sem grande resultado. Desanimado por isso, foi passar umas férias à beira-mar e, eis que, quando passeava pelas falésias, veio-lhe subitamente a solução. E assegura que não estava pensando na sua pesquisa.

Poincaré (1908, p. 4) tenta uma explicação:

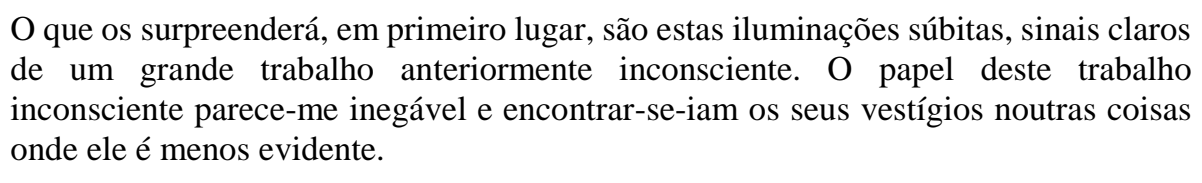

Testemunho comentado por Hadamard (2009, p. 27): “O surpreendente são essas aparências de iluminação súbita, sinais manifestos de um longo trabalho inconsciente; o papel desse trabalho inconsciente na invenção matemática parece-me incontestável. ” Ainda procura ele explanar o papel do inconsciente quando tenta conciliar o sono, "as ideias surgiram em borbotões" e, assim, parece que "a pessoa assiste seu trabalho inconsciente" (Idem, p. 29).

\subsection{A explicação de Poincaré}

Antes de relatar suas experiências nesta conferência, Poincaré (1908, p. 8) explica o que é a criação matemática e a descreve como combinações, não, porém, como fazer combinações com entes matemáticos já conhecidos, pois isto pode ser feito por qualquer pessoa, mas "criar consiste, precisamente, não em construir combinações inúteis, mas as que são úteis e que estão em ínfima minoria. Criar é escolher...” (Idem, p. 2).

As escolhas precisam, de fato, resolver os problemas tratados, apresentando as soluções verificáveis pelos métodos matemáticos. E essa capacidade de escolha não está ao alcance de todos. Essas escolhas felizes ou bem-sucedidas são as iluminações (insights) súbitas. Poincaré o afirma: "É manifesto que nem todos são capazes de criar” (Idem, ibidem). 
Para que aconteçam esses insights, portanto, não basta o trabalho e o esforço, é necessário, também, a capacidade, ou, expressando de outro modo, é preciso o que se denomina em filosofia de potencialidade, ou uma Zona de Desenvolvimento Potencial.

Ora, diz Hadamard, mais adiante (Idem, p. 10), “são estas as iluminações súbitas, sinais claros de um grande trabalho anteriormente inconsciente", trabalho este que se sucede a vários dias de trabalho consciente, intenso e constitui o que ele denomina de incubação.

Evidentemente este trabalho inconsciente não seria possível se não houvesse antes uma dedicação consciente em que se debruça sobre o problema ou a questão a investigar. Ele observa, ainda, que as iluminações súbitas apenas surgem após "alguns dias de esforços voluntários" (Idem, p. 11).

Poincaré não estava a par dos avanços e das descobertas da neurologia, sobretudo, após o conhecimento dos neurônios e de suas conexões (descobertas que não cessam de crescer e de se tornarem mais aprofundadas).

Feitas estas observações, entende-se a explicação de Poincaré que, além de apelar ao inconsciente, traz à baila a teoria do eu subliminar.

Surge-nos então uma primeira hipótese. O eu subliminar não é de forma alguma inferior ao consciente. Não é puramente automático, é capaz de discernimento, possui tacto, delicadeza. Como diria?... Adivinha melhor que o consciente uma vez que consegue chegar aonde este fracassou. Numa palavra, não será ele superior ao consciente? (Idem, p. 11).

Afirma, também, que estaria disposto a aceitar esta hipótese, mas, reconhece que este automatismo é "muito misterioso". Depois, alega a importância de a solução ser "estética", pois "não se deve esquecer o sentimento de beleza matemática" (Idem, p. 12). Então, o autor em tela expressa mais sua convicção do que um conhecimento baseado em dados empíricos que poderiam ser observados de maneira objetiva.

Como Jacques Hadamard se apoia na introspecção de experiências de matemáticos, citando, além dos depoimentos de Poincaré, expostos na citada conferência de 1908, Gauss (HADAMARD, 2009, p. 29-30) e os testemunhos de outras aéreas como os depoimentos de Mozart e de Paul Valéry (Idem, p. 29-31), entre outros. Esses exemplos ilustram o processo psicológico da invenção visto de maneira introspectiva.

Contudo, tanto Hadamard como Poincaré afastam a hipótese do acaso. O acaso pode ser definido como o "encontro de séries causais independentes". Em Acaso e Necessidade, Jacques Monod (2006) empresta a definição de Demócrito como a interferência de uma série de eventos totalmente dependentes que se encontram sem previsão. Por exemplo, escreve ele, o doutor $\mathrm{x}$ vai pela rua e, ao cruzar a esquina, em que há um prédio em construção, um tijolo cai sobre a 
cabeça de x, e este morre. Foi uma morte acidental, um acaso. O apelo ao acaso é um recurso à ignorância.

Se não conhecemos essas ocorrências não há possibilidade de serem previstas, como não podemos antecipar as iluminações, e esta é a coincidência com os eventos que se dão ao acaso.

Por isso, Hadamard afirma, e com ele concordamos, que a iluminação não se produz ao acaso. Há um trabalho do inconsciente ou do subconsciente, como quando nós falamos, não prevemos conscientemente a frase que vai se suceder, mas é "escolhida" por combinações inconscientes. A explicação que fornece é que as iluminações, ou atos que resultam por hábito, são frutos de um trabalho mental inconsciente.

O inconsciente tem um caráter múltiplo. Como é que nós reconhecemos, sem intermediário, o rosto de um conhecido ou a voz de uma pessoa que é do nosso meio? As características do rosto de um amigo devem estar presentes no espírito, no inconsciente. A Neurologia explica tal ocorrência por "gravações" realizadas no cérebro através das sinapses, em seguida, modificadas e armazenados em dendritos, conforme explica Eric Kandel (2007) e Larry Squire (2003).

Ao tratar das diversas modalidades do inconsciente, Hadamard refere-se à chamada consciência marginal. Cita, então, Galton supondo a existência de uma espécie de "antecâmara" da consciência.

\begin{abstract}
Quando estou meditando sobre alguma coisa, parece que o processo dessa meditação é o seguinte: no momento qualquer, as ideias que estão em plena consciência parecem atrair as mais apropriadas entre o certo número de outras ideias, que se encontram próximas, embora imperfeitamente alcance do inconsciente. Tudo se passa como se houvesse em meu espírito uma sala de audiência onde a plena consciência comanda e onde duas ideias comparecem simultaneamente; e, ao mesmo tempo uma antecâmara cheia de ideias mais ou menos aparentadas, situada fora do campo de visão da plena consciência. Vindo dessa antecâmara, as ideias mais relacionadas com as que estão em sala de audiência relacionadas com as que estão na sala de audiência parecem ser convocadas de uma maneira mecanicamente lógica, cada uma tendo sua vez na audiência (GALTON, 2004, p. 146).
\end{abstract}

Hadamard explica a invenção pela combinação de ideias, como o fez Poincaré (1908, p. 2). Ideias combinadas de maneira aleatória, estocástica, no inconsciente produzem muitas combinações, entre as quais, o inconsciente opera a seleção (escolha) cujo resultado é o que ele denomina de iluminação.

Portanto, sintetizando o pensamento de Hadamard, apoiado nas descrições das introspecções dos matemáticos e artistas citados, a iluminação exige uma preparação e um trabalho consciente. Se este trabalho não produzir resultado, "esquece-se", isto é, deixa-se de trabalhar nele e faz-se outra coisa, ou repousa-se, descansado, dormindo ou saindo de férias. 
Esse tempo é denominado de incubação, que, para o dicionário Aurélio, vem de incubar, cujo significado é chocar, possuir em estado latente, premeditar, planejar, planear, projetar.

Assim, a invenção matemática é como uma construção livre do pensamento, sem as coações empíricas, nem como fruto de induções lógicas, a partir de dados da experiência. Não seria, pois, um salto indutivo, como pretendia Aristóteles, nem pode a invenção ser considerada como descoberta das ideias inatas platônicas por estarem já impressas na mente das pessoas. Portanto, não seria fruto de inatismo.

Contudo, não se pode deixar de relacioná-las com a intuição, como a define Descartes. Este filósofo, mais do que qualquer outro, deu muito espaço à intuição, uma vez que era, a seus olhos, na intuição que ocorria a iluminação das evidências que constituíam para ele o momento do entendimento, ampliado pelo raciocínio que exige dedução e memória, além de estar vinculado à evidência pelas constituições das certezas. Porém, era uma intuição racional, entendida, acima de tudo, como uma função sintética da compreensão.

\section{A SALA DE AULA DE MATEMÁTICA}

Tratamos até o momento de como se processa a invenção matemática pela via introspectiva, segundo Hadamard. Surge, então, a questão do ensino, o saber da didática: Os que planejam os currículos estão cientes destas pesquisas? O currículo das escolas regulares ou das universidades, por eles elaborados, permitem aos alunos tempo para pensar e refletir sobre problemas aparentemente insolúveis? Consideram a importância dos fatores inconscientes na aprendizagem? Os professores estão preparados para trabalhar de forma criativa que favoreçam a descoberta e a criação? Os docentes sabem como ocorre a invenção matemática? (porque todo insight pode ser aproximado de uma invenção). As formações inicial e continuada dos professores de matemática promovem discussões sobre uma metodologia que promova a flexibilidade no pensamento para conceber diferentes categorias de respostas? Essas são algumas questões iniciais para pensarmos na possibilidade de termos alunos como sujeitos ativos em seu processo de aprendizagem.

Para avançarmos nesse ensaio, faremos uma imersão na sala de aula de matemática, discutindo sobre suas características e fenômenos que emergem no cenário didático. Além disso, buscaremos identificar possibilidades de inserir as ações de descoberta e de criação em seu cotidiano.

Muito se fala sobre as dificuldades dos alunos com a matemática. Os resultados dos exames traçam um cenário catastrófico. Alguns pesquisadores (ARAÚJO, 2009; BRITO 
MENEZES, 2006; MENEZES, 2004) defendem que esses resultados não são consequência da incapacidade dos alunos, mas sim, da inadequação dos métodos de ensino. Esses pesquisadores afirmam que essa disciplina precisa ser vista como uma ciência viva, útil à sociedade, significativa e prazerosa. Existem formas divertidas, instigante, significativa de compreendê-la e identificá-la, tanto na vida social, econômica, cultural, quanto na tecnologia.

É consenso entre os professores que os conteúdos da matemática são absolutamente fundamentais para o desenvolvimento mental do educando e não é possível desassociá-los da vida das pessoas, está presente no cotidiano de forma marcante em tudo o que fazemos. Mas, por que isso não ocorre na sala de aula de matemática? Segundo Libânio (2004) e Demo (2007), a formação continuada é imprescindível para superação dos entraves que se encontram na sala de aula, principalmente em matemática, em que identificamos um baixo rendimento nas avaliações externas.

Os dados do Sistema de Avaliação da Educação Básica (SAEB), em 2017, divulgados pelo Ministério da Educação (MEC) apontam que, em matemática, 71,67\% dos alunos têm nível insuficiente de aprendizado. Desses, 23\% estão no nível 0 - o mais baixo da escala de proficiência. Esses dados indicam uma ineficácia no processo de ensino-aprendizagem. Contudo, quando refletimos sobre esse processo, acompanhamos Chevallard:

\footnotetext{
Outra digressão: muitas vezes vejo as palavras ensino e aprendizagem. Na TAD, falamos em estudo, os alunos estudam, não dizemos que os alunos aprendem. Por quê? Porque a aprendizagem não é algo seguro. Quando estudo, às vezes, não aprendo nada. Os alunos estudam e os professores os ajudam a estudar. (CHEVALLARD, 2019 , n.p.)
}

Nesse sentido, se o professor não conseguiu ajudar os alunos a estudar, consequentemente, eles não aprenderão. Como podemos modificar nossa prática e ajudar nossos alunos a aprender? Ou, quem sabe, fazer descobertas ou invenções (fazendo um paralelo com Hadamard)?

Apesar de não termos, em nenhum momento, limitado o espaço escolar nesse ensaio teórico, entendemos que, a Educação Básica, é o campo fértil para as descobertas de conceitos e, em contrapartida, o Ensino Superior será o espaço ideal para a invenção de modelos e saberes importantes para o desenvolvimento de uma sociedade. É essencial deixar claro que, não pensamos que esses espaços (a Educação Básica e o Ensino Superior) sejam limitados a cumprir apenas uma dessas ações descobrir e inventar, respectivamente, isso dependerá dos diversos fatores envolvidos para a aquisição dessas ações. Contudo, essas possibilidades só serão 
contempladas, caso a prática do professor, em sala de aula, permita que ocorram momentos favoráveis a criatividade.

A atividade docente carrega características próprias que estão para além da sala de aula, ou seja, é bastante comum que o professor seja conduzido a tomar decisões importantes em diversos momentos durante sua profissão. Percebe-se que antes de entrar em sala, na preparação bimestral, semestral ou anual, por meio de planejamentos elaborados, são solicitados aos docentes os planos de ensino, explicitando os objetivos, metodologias, recursos e a avaliação dos conteúdos a serem trabalhados. Todavia, alguns elementos emperram a execução de um bom planejamento: os recursos pedagógicos disponíveis, a limitação do tempo pedagógico, falta de autonomia didático-pedagógica, falta de apoio para trabalhos em equipe e problemas financeiros.

Enfim, são diversos os entraves que desfavorecem a construção de um planejamento voltado às ações mais ativas do aluno em sala de aula, implicando, assim, em aulas que conduzem a uma ação mecânica, estática e enfadonha, voltada inteiramente para a memorização, longe de permitir-lhe uma construção de sua própria linha de raciocínio, levandoo a se aventurar pelo mundo da matemática, a fim de explorar novas situações.

De modo geral, as salas de aulas de matemática se caracterizam por apresentar conceitos e procedimentos em atividades já resolvidas, seguidas de atividades propostas, predominantemente de fixação. Há pouco espaço para a participação do aluno na construção das ideias, e a aplicação de algoritmos e procedimentos é privilegiada. Tal escolha oferece a esse aluno poucas oportunidades de construir o seu conhecimento. Muitas vezes, o seu papel restringe-se à memorização, aplicação de regras e procedimentos.

Conrad Wolfram (2010), em uma fala no TED, afirma, e com razão, que os professores de matemática passam dois terços do tempo das aulas fazendo cálculos que o computador faria em segundos. Quando os alunos se ocupam com cálculos, não estão atentos para saber qual é a real pergunta do problema ou qual a relação da formulação matemática com a sua aplicação na realidade? São essas questões que requerem invenção, criatividade e inovação.

Apesar de numerosas, as atividades sugeridas não colaboram muito para o desenvolvimento de competências complexas como investigar, estabelecer relações, argumentar, conjecturar, entre outras. Para alguns autores (FONSECA 2004; BOSCH; FONSECA; GASCÓN; 2004; FONSECA; BOSCH; GASCÓN, 2007) as organizações matemáticas estudadas no Ensino Fundamental dos Anos Finais (alunos de 11-14 anos) são pontuais, rígidas e pouco articuladas entre si. Isso reforça a ideia de um ambiente refratário à expressão da criatividade. 
Mas, o que favorece a termos esse ambiente tão rígido da sala de aula de matemática e que não desperta a possibilidade de descobertas e criações? Para responder a essa questão, é necessário avançar sobre alguns fenômenos didáticos que emergem no cenário didático. Assim, agora, debruçar-nos-emos sobre os fenômenos da Transposição Didática e do Contrato Didático.

\subsection{Fenômenos Didáticos que emergem na sala de aula}

Os fenômenos didáticos são aqueles que se instituem numa sala de aula, envolvendo a tríade professor-aluno-saber, quando é estabelecida uma relação didática. A Transposição Didática foi um fenômeno investigado por Yves Chevallard (1991), dentre outros, e analisa a trajetória que cumpre o saber, desde a sua produção científica, até a sua inserção no universo da sala de aula. O Contrato Didático, por sua vez, foi estudado inicialmente por Guy Brousseau (1986), e diz respeito às cláusulas, em parte explicitadas, mas, na sua maioria, implícitas, que regulam a divisão de responsabilidades entre professor e aluno, na gestão de um saber.

A literatura tem tratado, até então, de ambos os fenômenos de forma distinta, pois, boa parte dos estudos acerca da Transposição Didática refere-se à sua primeira etapa: a Transposição Didática Externa. Assim, suas inter-relações com o Contrato Didático não são tão discutidas, uma vez que este último fenômeno acontece no interior da sala de aula, na relação didática permeado pela Transposição Didática Interna.

\subsubsection{Transposição Didática}

Destacamos um impasse no processo e nas relações constituídas na configuração do sistema didático: o distanciamento que o conteúdo matemático trabalhado em sala de aula apresenta em relação às fontes legítimas do saber em questão. Tal distanciamento é proveniente das "transformações" que os saberes acadêmicos ou científicos sofrem para se tornarem saberes escolares (objetos de ensino). A todo esse processo, Yves Chevallard (1991) denomina de transposição didática, um conjunto de modificações que tornam um saber, digamos teórico, acessível aos alunos, por meio de um processo de didatização. Trata-se de um processo evolutivo em que um saber científico, aquele produzido na academia por especialistas, sofre algumas modificações até chegar aos intramuros da escola, ocasionadas pela elaboração de programas nacionais, como também pela subjetividade do professor ao preparar a aula sobre um determinado saber a ser ensinado. Ainda, pode-se levar em consideração o saber que se 
efetiva como aprendido pelo aluno. Em alguns países, essas modificações começam a aparecer no conteúdo dos programas e nos manuais de ensino.

Por outro lado, existem, também, as pressões externas para a apresentação desse saber à sociedade. Os saberes comunicados, inicialmente no mundo acadêmico e científico, necessitam de um novo tratamento, no sentido de que sua roupagem mais acadêmica seja retirada e que ele possa, após essa primeira deformação, ser comunicado, compreendido e, se possível, utilizado socialmente num período breve. Uma vez produzido e comunicado, o saber necessita, agora, passar pelas adaptações para que se torne ensinável.

O longo processo de transformação dos saberes científicos em saberes a ensinar é realizado no espaço que Chevallard intitula de "noosfera" e que envolve a comunidade (pessoas e instituições) responsável por estabelecer o que deve ser ensinado na escola. Podemos, nesse sentido, referirmo-nos aos didatas, professores, pedagogos, técnicos de instituições e governos responsáveis por gerir o ensino (no caso do Brasil, o MEC, por exemplo). Enfim, pessoas (muitas delas representando instituições) que vão elaborar programas, diretrizes curriculares, livros didáticos, os quais aparecem, então, como instrumentos reguladores, no sentido de que eles irão normatizar o que deve ser ensinado na escola, o saber a ensinar.

Essas diferenças nos saberes, conforme passam por diferentes estágios - antes de entrarem em sala de aula, na preparação e quando são verbalizados pelo professor - parecem se dar por vários motivos: concepções de ensino, formação pedagógica, influências da escola, projetos pedagógicos, entre outros. Porém, a relação pessoal que o professor tem com o objeto de ensino nos mostrou estar sempre presente para que essas diferenças ocorressem. Ela parece servir como um "núcleo duro", uma espinha dorsal, para que esse processo de Transposição Didática Interna exista. A escolha na condução do conteúdo, o tempo de permanência do saber no cenário didático, as criações didáticas realizadas, as relações que estabelecem entre os conteúdos tratados e a forma como tratam os conteúdos reforçam a ideia de que a forma como o saber chega ao aluno, por parte do professor, dá-se, primeiramente, por essa ligação intrínseca professor-saber.

Para Javier Morrero Acosta (2013, p. 193), “o professor tem de aprender a adequar, de forma didática, o conhecimento de acordo com as características do aluno e do conteúdo, a fim de que ele seja transmitido da forma mais adequada (...) a passagem do saber sábio para o saber ensinado". Contudo, percebe-se na escola, que, embora a escolaridade busque encorajar a resolução de problemas, uma desconsideração da maioria das heurísticas inventivas que os alunos trazem para a sala de aula. 


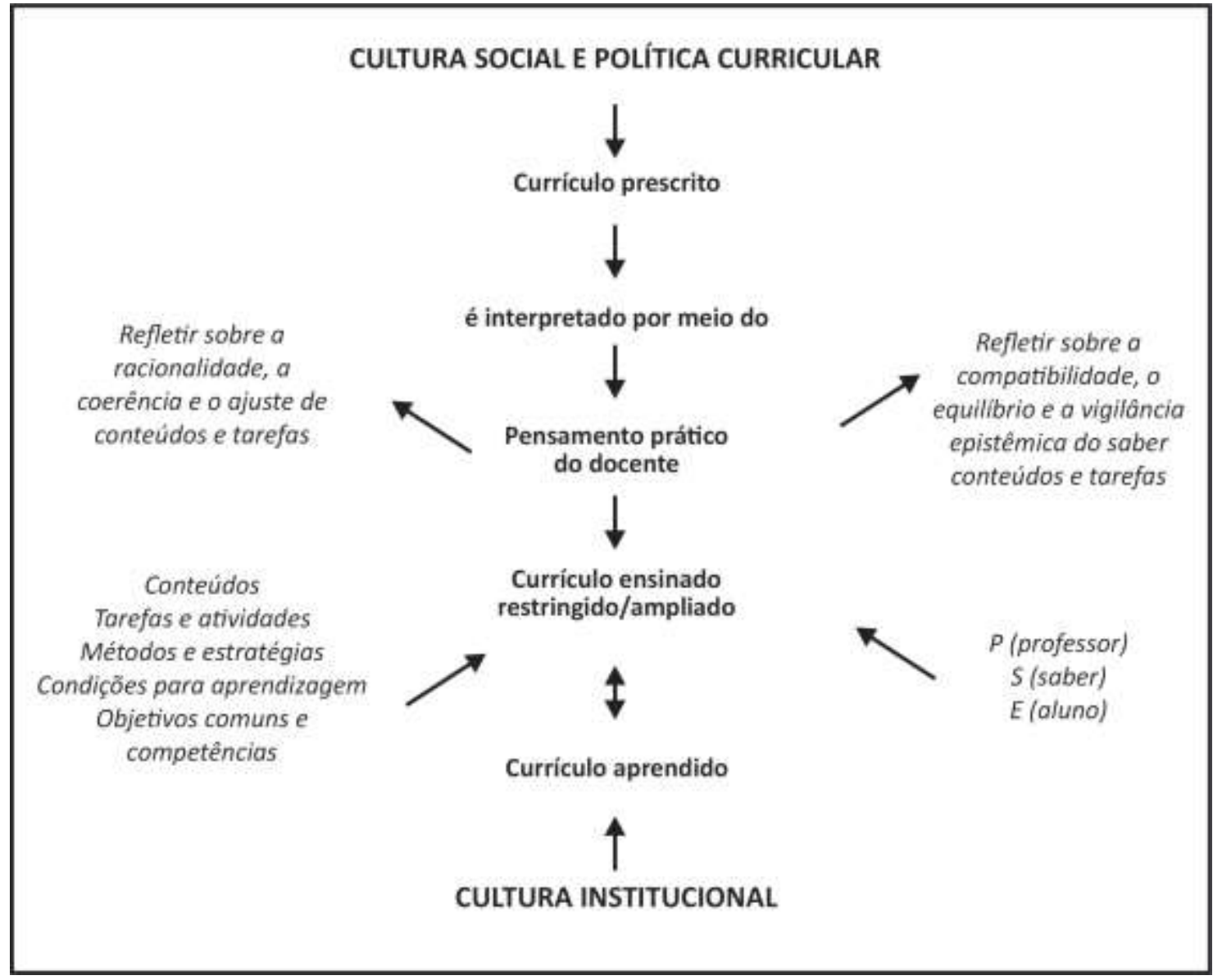

Figura 1 - Saberes, processos e esferas de decisão do que se ensina.

Fonte: Acosta (2013).

Tanto na Figura 1, como em Chevallard, não aparecem considerações sobre a incubação, preparação, iluminação e verificação, que correspondem ao espaço para invenção, maturação, repouso e emergência da criatividade dos alunos. Não que a afirmação a seguir se refira a Chevallard, ou outros, porém, Robinson (2006) em sua palestra "Será que a escola mata a criatividade?" nos faz refletir que a escola mata a criatividade dos alunos, porque infundiu neles o medo de errar. Parece que os alunos são gênios quando crianças e que a escola trata de tornálos medíocres pelo engessamento, não se lhes permite pensar fora do quadrado em que domina o saber do professor detentor do saber. É necessário que se deixe tempo aos alunos para que aprendam ou resolvam problemas no seu ritmo e que possam inventar estratégias.

Ao pensar na coletividade (alunos), o sistema educacional esquece da individualidade e da capacidade de resolução de problemas inventivos. Os pesquisadores Brown, John; Collins, Allan e Duguid, Paul (1989) nos apontam que alguns estudantes acham necessário disfarçar estratégias eficazes para que os professores acreditem que os problemas foram resolvidos da maneira aprovada. Essa necessidade de repetir o mesmo caminho de resolução que o professor apresenta, reforça o pensamento de Habermas, que aponta que o valor prático do saber não 
reside mais em sua capacidade de melhorar as pessoas e, por meio da racionalidade proporcionada, permiti-lhes uma vida mais livre e mais humana, pelo contrário, tudo tem de refletir na produtividade econômica. O autor ainda avança "A ciência distanciou-se da formação, à medida que impregnou a práxis profissional" (HABERMAS, 1987, p. 338).

Outro viés sobre as variações no saber, dá-se, em princípio, pela ideia que o professor possui de seus alunos, quais seriam seus obstáculos, dificuldades, facilidades, enfim, toda uma análise preliminar do que ocorreria em sala de aula. Porém, essas análises preliminares nem sempre se concretizam, fazendo com que o papel do professor seja de reorientar a condução do saber em sala de aula. Essa fase da transposição está intimamente ligada ao Contrato Didático, ou seja, às expectativas que professores e alunos têm entre si.

\subsubsection{Contrato Didático}

A relação que se estabelece entre professor e aluno - com vistas à apropriação do saber - tem, na sua base, regras que determinam quais as responsabilidades de ambos os parceiros na relação didática. Responsabilidades estas que irão gerenciar a negociação de significados e, consequentemente, a apropriação do saber. Tais regras constituem o contrato didático (BROUSSEAU, 1996; CHEVALLARD; BOSCH; GASCÓN, 2001), e, como o próprio conceito propõe, não são, em sua maioria, explicitadas, mas, ao contrário, frequentemente implícitas e se revelam principalmente quando transgredidas por uma das partes envolvidas.

Chevallard (1999) discute que, no contexto escolar, existem outras modalidades de contrato que, muitas vezes, são confundidas com a própria noção de contrato didático. Nesse sentido, ele aponta para a existência de dois outros tipos, mais gerais: o contrato pedagógico e o contrato escolar. No caso do contrato pedagógico, ele regula as interações entre professor e aluno, sem, contudo, estar vinculado a nenhum conteúdo curricular específico. O contrato escolar, por seu turno, pode ser entendido como aquele que governa as instituições sociais escolares.

Podemos observar que estes três tipos de contratos se encontram relacionados, embora se manifestem em diferentes níveis. O contrato escolar é o mais amplo de todos e rege a relação aluno-escola. O pedagógico aparece em nível um pouco mais restrito, pois diz respeito não somente à instituição, mas aos parceiros: professor e aluno, tomados independentemente do conhecimento em questão. Em relação ao contato didático, Chevallard (op.cit.) propõe que "a passagem do contrato pedagógico para o contrato didático acontece quando a relação entre os dois (professor e aluno) se transforma realmente na relação entre três: o aluno, a obra a ser 
estudada e o professor como coordenador de estudo" (p.235). E completa: "sem esquecer a interdependência entre os três níveis (o escolar, o pedagógico e o didático), cabe lembrar que o contrato didático é a pedra de toque de toda a organização escolar” (p.236).

Nos últimos anos, alguns desses elementos estão sendo reestruturados, pois a interação em sala de aula e a participação do aluno como 'sujeito do conhecimento' têm sido estimuladas na relação didática. No momento em que o aluno interage com instrumentos como o computador, o professor deixa de ser o elemento central do processo, mas passa a ter um novo papel - e de extrema responsabilidade - o de mediar e coordenar as atividades, compartilhando e negociando significados com os alunos.

\subsection{Discurso Educacional e o momento da invenção matemática}

Considerando os fenômenos aqui abordados - transposição didática e contrato didático -, Brito Menezes (2006) aponta que um importante instrumento para análise desses fenômenos é o discurso educacional. Ainda segundo Brito Menezes (2006, p. 67), sendo a relação didática formada por dois elementos humanos e subjetivos - professor e aluno - “(...) não podemos deixar de considerar seu próprio discurso ou, mais além, a interação discursiva estabelecida entre o professor e aluno, com vistas à apropriação de um saber.”

O interesse pela análise do discurso educacional remonta à discussão sobre como se dá o processo de ensino-aprendizagem, no contexto da sala de aula, a partir de uma perspectiva teórica sociocultural, notadamente pelos estudos de Vygotsky e, posteriormente, por outros teóricos.

Nessa perspectiva, a apropriação do saber não se dá de maneira direta: ela é, em essência, mediada por sistemas simbólicos (VYGOTSKY, 1984; VYGOTSKY, LURIA, LEONTIEV, 1998). Dentre os chamados 'sistemas simbólicos', a linguagem assume um papel relevante. É ela a principal responsável pela transmissão cultural, na abordagem vygotskiana, e o principal instrumento simbólico mediador na sala de aula. É mediante a linguagem que professores [e alunos] organizam, propõem e executam sequências de atividades que possibilitam, nas suas múltiplas interações, negociar e compartilhar significados.

Se ampliarmos a ideia de linguagem enfocada pelas teorias socioculturais, e considerando a importância no contexto da educação, caminhamos em direção à investigação do discurso educacional como ferramenta essencial na análise dos fenômenos didáticos. A concepção de 'discurso', nessa linha de pensamento, amplifica a concepção de linguagem, podendo o discurso ser entendido, então, como 'linguagem em ação' (COLL, 1998). 
Ao referirmo-nos ao 'discurso', algumas questões necessitam ser cuidadosamente abordadas. A primeira delas diz respeito à seguinte constatação: a maioria dos estudos sobre o tema analisa o discurso unicamente do ponto de vista docente (CANDELA, 1998). Nessa linha de estudos, quase sempre se exclui o aluno como sujeito no processo discursivo, o que, numa análise mais rigorosa, pode nos conduzir à visão do professor como aquele que 'transmite' o conhecimento - via discurso - em que o aluno é percebido como um mero 'receptor'.

Nesse sentido, temos observado em sala de aula que alguns alunos, na verdade, têm um papel "mais ativo", independente do contrato estabelecido, pois "decodificam" os saberes transmitidos de forma particular. No mesmo momento em que o professor verbaliza o saber, ou seja, transforma o saber matemático em palavras, o aluno faz o caminho inverso, transforma as palavras no saber matemático.

E acreditamos, que essa decodificação possa ser realizada por meio das suas próprias experiências anteriores, sua subjetividade, o que poderá criar um novo conhecimento com características e organizações particulares, que se ajustam e "funcionam" na resolução das tarefas, mesmo que não tenham uma justificativa coerente para esse novo conhecimento.

E será nesse momento de decodificação que poderão surgir as descobertas e as criações por parte dos alunos, pois é o período em que reflete para dar a si mesmo um significado ao que está sendo estudado. São momentos particulares em que se percebe a possibilidade de se estabelecer as fases da invenção matemática expostas na Psicologia da invenção matemática de Hadamard - preparação, incubação, iluminação e verificação. Contudo, será necessário que o professor esteja atento e permita que o aluno tenha o tempo exigido para essa maturação do saber, não antecipando as respostas e interferindo na construção do conhecimento no cenário didático, o que é habitual em uma sala de matemática. Em geral, os professores não se mostram pacientes para esperar que os alunos, seja refletindo, seja interagindo com os colegas, possam pensar em estratégias próprias para a solução dos problemas. É necessário respeitar o ritmo dos discentes.

Apesar de termos clareza dessas concessões de tempo, o professor ainda se encontra nas amarras de um currículo prescrito que prevê uma temporalidade própria para o cumprimento de um conteúdo a ser apresentado em sua rotina escolar. Esse talvez seja o grande entrave da expectativa de um planejamento que permita a descoberta e a criação em sala de aula.

Outro ponto, já discutido, que inviabiliza esse planejamento, é a realidade da maioria das salas de aula de matemática, em que encontramos o conteúdo trabalhado apenas na aplicação de fórmulas e resolução de listas de exercícios de forma mecanizada e cansativa. Essa prática docente está ancorada no que o professor acredita sobre o que é ensinar e aprender. Sem 
uma alteração nessa concepção, não poderemos ter salas que permitam que se desenvolva a criatividade, essencial para novas descobertas e criações.

\section{CONSIDERAÇÕES FINAIS}

O desenho que descrevemos nesse ensaio, parece-nos transparecer a necessidade de que os docentes estudem, ou na formação inicial ou continuada (ou, até mesmo, por conta própria, autodidaticamente), os avanços, tanto da psicologia da aprendizagem, como da neuroepistemologia, atualmente desconhecida pela grande maioria desses docentes.

Nessa perspectiva de aquisição desses avanços, percebe-se que as fases que Hadamard denomina preparação (visualização e manipulação) e verificação (experimentação) permitem o trabalho do inconsciente na incubação da qual emerge a iluminação. Contudo, alguns aspectos implícitos nos processos de aprendizagens e no desenvolvimento cognitivo estudantil, não são objetivamente trabalhados no currículo escolar. Dentre eles, devemos considerar a autonomia que um indivíduo exerce diante de qualquer realidade ao agir sem o suporte direto de outra pessoa. Nesse sentido, entendemos que a autonomia não deve ser apenas considerada, mas orientada para que o estudante tenha a mediação docente, tanto para que apreenda os conceitos necessários, como também, domine o processo de aprendizagem como parte da sua formação.

$\mathrm{Na}$ busca de responder os questionamentos que nos orientaram nesse ensaio, percebemos que a falta de autonomia dos discentes é rotineiramente observada em sala de aula, quando alguns estudantes repetem estratégias eficazes, apresentadas pelos professores, fazendo com que acreditem (os professores) que os problemas foram resolvidos de maneira adequada. Essa necessidade de repetir o mesmo caminho de resolução que o professor apresenta - esse condicionamento dos alunos em repetir os modelos de resolução difundidos pelos docentes - é reforçado pelo fenômeno do Contrato Didático estabelecido no cenário didático, ou seja, as expectativas do professor e dos alunos, um ensina o que é para ser feito e os outros aprendem ao reproduzi-lo.

Portanto, a partir dos estudos de Hadamard e nos depoimentos de Poincaré, formulamos a hipótese de que nas aulas de matemática é necessário incentivar a autonomia na aprendizagem e estimular os discentes a se tornarem criativos e inventivos. Contudo, para comprovar se a didática da matemática incentiva os alunos a serem criativos e inventivos seriam necessárias pesquisas de campo, o que não foi o objetivo do estudo ora apresentado. 
Segundo o resultado das pesquisas relatadas, é necessário evitar que as aulas sejam simples transmissoras de conteúdos de que os discentes deveriam se apropriar. Não se pode mais adotar o formato reducionista do processo de aprendizagem, pois parece-nos (diminuir espaço) estar ligado ao valor prático do saber, em que se prioriza a sua serventia contingente e particular e, consequentemente, distanciando-se do acesso aos saberes elaborados socialmente, os quais se constituem como instrumentos para o desenvolvimento, a socialização, o exercício da cidadania e a atuação, no sentido de reformular os conhecimentos, as imposições de crenças e valores.

Na sala de aula, construir uma prática pedagógica voltada à criatividade, em que assume um papel importante na trajetória do aluno é fundamental. Seguindo esse pensamento, a Base Nacional Comum Curricular (BNCC) já aponta para essa necessidade, considerando a criatividade como parte das competências socioemocionais previstas no documento. Essas características propõem o desenvolvimento do aluno como um cidadão completo, emocionalmente preparado para ter sucesso, tanto nas relações pessoais, quanto nas habilidades profissionais, no futuro.

Para isso, romper com os modelos pré-estabelecidos nos papeis do professor e dos alunos em sala de aula são essenciais; criar estratégias e atividades que possam permitir momentos de visualização, manipulação e experimentação que estimulem o pensamento criativo, em todos os alunos, é um dos grandes desafios para os educadores. Portanto, o professor não pode se comportar como o detentor do saber e seus alunos como simples receptores de informações, seu papel será de mediador entre o conhecimento trabalhado, e os alunos permitindo-o criar ou descobrir novos conhecimentos. O docente assim deixará espaço para que os alunos tenham tempo para a incubação e então emergirá a inventidade e criatividade dos alunos.

Oxalá, as considerações apresentadas possam sensibilizar os docentes para refletirem sobre sua nobre missão de ensinar e de educar.

\section{REFERÊNCIAS}

ACOSTA, J. M. O currículo interpretado: o que as escolas, os professores e as professoras ensinam? In: SACRISTÁN, J. G. Saberes e incertezas sobre o currículo. Porto Alegre: Penso, 2013, p. 188-208.

ARAÚJO, A. J. O ensino de álgebra no Brasil e na França: estudo sobre o ensino de equações do $1^{\circ}$ grau à luz da teoria antropológica do didático. Tese de Doutorado em Educação, Recife, Universidade Federal de Pernambuco, 2009. 
BERGSON, H. Le rêve. Bulletin de l'Institut psychologique, 1901 (réédité dans l'Énergie spirituelle. Paris, Alcan. 1919).

BOSCH, M. C.; FONSECA, C. B. e GASCÓN, J. Incompletitud de las Organizaciones Matemáticas Locales en las instituciones escolares. In: Recherches en Didactique des Mathématiques, $\mathrm{n}^{\circ}$ 24/2.3, 2004, p. 205-250.

BRITO MENEZES, A. P. Contrato Didático e Transposição Didática: Inter-relações entre os fenômenos didáticos na iniciação à álgebra na $6^{a}$ série do Ensino Fundamental. Tese de Doutorado em Educação, Recife, Universidade Federal de Pernambuco, 2006.

BROUSSEAU, G. Fondements et méthodes de la didactique. In: Recherches en Didactique des Mathématiques, n. 7.2. La Pensée Sauvage, Grenoble, 1986, p. 33-115.

. Os diferentes papéis do professor. In: PARRA, C. \& SAIZ, I. (Orgs.). Didática da Matemática: Reflexões Psicopedagógicas. Porto Alegre: Artes Médicas, 1996, p. 48-72.

BROWN, J.; COLLINS, A. e DUGUID, P. Situated Cognition and the Culture of Learning Educational Researcher, Vol.18, No.1. 1989, p.32-42, jan.-fev.

CANDELA, A. A construção discursiva de contextos argumentativos no ensino de ciências. In: COLL, C. e EDWARDS, D. (Orgs.) Ensino, aprendizagem e discurso em sala de aula: aproximações ao estudo do discurso educacional. Porto Alegre: ArtMed, 1998.

CHEVALLARD, Y. La transposition didactique. Grenoble, La pensée Sauvage, 1991.

L'analyse des pratiques enseignantes en Théorie Anthropologie Didactique. In:

Recherches en Didactiques des Mathématiques, 1999, p. 221-266.

BOSCH, M. \& GASCÓN, J. Estudar Matemáticas: O Elo Perdido entre o Ensino

e a Aprendizagem. Porto Alegre: Artes Médicas, 2001.

Palestra de Encerramento do Advanced Course 2: Teacher Education and the Professionalization of Teaching, Universitat Autònoma de Barcelona - UAB Barcelona/ Campus de Bellaterra, Barcelona, jun. 2019. Não paginado.

COLL, C. S. A construção de significados compartilhados em sala de aula: atividade conjunta e dispositivos semióticos no controle e acompanhamento mútuo entre professor e alunos. In: COLL, C. \& EDWARDS, D. (Orgs.) Ensino, Aprendizagem e Discurso em Sala de Aula: Aproximações ao Estudo do Discurso Educacional. Porto Alegre: Artes Médicas, 1998.

DEMO, P. É preciso estudar. In: Britto A. M. (Org.). Memórias de formação: registros e percursos em diferentes contextos. Campo Grande: Ed. da UFMS, 2007.

FONSECA, C. B. Discontinuidades Matemáticas y Didácticas entre la Secundaria y la Universidad. Tesis doctoral. Universidad de Vigo, 2004.

FONSECA, C. B.; BOSCH, M. C. e GASCÓN, J. El momento del trabajo de la técnica en la completación de organizaciones matemáticas: el caso de la «Regra de Ruffini». In: L. RuizHigueras, A. Estepa \& F. J. García (Orgs.), Sociedad, escuela y matemáticas. Aportaciones 
de la teoría antropológica de lo didáctico (TAD). Jaén, España: Publicaciones de la Universidad de Jaén, 2007, p. 139-158.

GALTON, F. Inquiries into Human Faculty: Psychometric Experiments. First electronic edition, 2001. Based on the text in the (Everyman) Edited by Gavan Tredoux. 2004, p. 146. This edition forms part of the online Galton archives at http://galton.org/This is the first corrected proof. Acesso em 22 abr. 2020.

HABERMAS, J. Teoría y práxis: estúdios de filosofia social. Madrid: Tecnos, 1987.

HADAMARD, J. S. Psicologia da invenção na matemática. Rio de Janeiro: Contraponto, 2009.

KANDEL, E. In search of memory: the emergence of a new science of mind. New York: W W Norton, 2007.

LEGLU, Dominique. Un problème de maths . Les mathématiques relèvent-elles de l'invention ou de la découverte? C'est l'une des questions posées pendant la Semaine de la science. https://www.liberation.fr/sciences/1999/01/26/un-probleme-de-maths-les-mathematiquesrelevent-elles-de-l-invention-ou-de-la-decouverte-c-est-l-une_262135, 26 janvier 1999. Acesso em 20/05/2020.

LIBÂNEO, J. C. Organização e Gestão da Escola: Teoria e Prática. Goiânia, Editora Alternativa, 2004.

MENEZES, M. B. Investigando o processo de transposição didática interna: o caso dos quadriláteros. Dissertação de Mestrado em Educação, Recife, Universidade Federal de Pernambuco, 2004.

MONOD, J. O Acaso e a Necessidade. 6 ed. Petrópolis: Vozes, 2006.

MORGAN, G. Paradigms, metaphors and puzzle solving in organization theory. Administrative Science Quarterly, v. 25, n. 4, 1980, p. 605-622.

POINCARÉ, Henri. L'invention mathématique. In: Bulletin de l'Institut Général de Psychologie, 8 è année, (nº 3), 1908, p. 175-196.

A invenção matemática. In P. Abrantes, L. C. Leal, \& J. P. Ponte (Eds.), Investigar para aprender Matemática. Lisboa: Projecto MPT e APM, 1996, p. 7-14.

RIBOT, T. A. Lèssai sur IÌmagination Créatrice. Alcan, 1 vol. 8, 1900.

SQUIRE, L. R. e KANDEL, E. R. Memória da Mente às Moléculas. Porto Alegre, Artmed, 2003.

ROBINSON, K. Palestra proferida no TED Taks, Monterey (California), fev. 2006. Disponível em: http:www.ted.com/talks/ken_robinson_says_schools_kill_creativity.html. Acesso em 10 jan. 2020.

VYGOTSKY, L. S. A Formação Social da Mente. São Paulo: Martins Fontes, 1984. 
; LURIA, A. R. \& LEONTIEV, A. Linguagem, Desenvolvimento e Aprendizagem. $6^{a}$ edição. São Paulo: Ed. Ícone (USP), 1998.

WOLFRAM, C (2010). Palestra proferida no TED Taks, Monterey (California), jul. 2010. Disponível em:

https://www.ted.com/talks/conrad_wolfram_teaching_kids_real_math_with_computers. Acesso em 10 jan. 2020.

Submetido em: 03 de agosto de 2020 .

Aprovado em: 23 de setembro de 2020. 